\title{
Bacillus Subtilis Spores as Delivery System for Nasal Plasmodium Falciparum Circumsporozoite Surface Protein Immunization in a Murine Model
}

Maria Edilene M. de Almeida

Postgraduate Program in Cellular and Molecular Biology at Oswaldo Cruz Institute, Rio de Janeiro, RJBrazil

Késsia Caroline Souza Alves

Postgraduate Program in Biotechnology, Institute of Biological Sciences, Federal University of Amazonas

Maria Gabriella Santos de Vasconcelos

Fametro University Center, Manaus

Thiago Serrão Pinto

Leônidas e Maria Deane Institute- ILMD-FIOCRUZ-AM

Juliane Corrêa Glória

Postgraduate Program in Biotechnology, Institute of Biological Sciences, Federal University of

Amazonas

Yury Oliveira Chaves

Postgraduate Program in Parasitic Biology, Oswaldo Cruz Institute, Rio de Janeiro, RJ

Walter Luiz Lima Neves

Foundation of Hematology and Hemotherapy of Amazonas, HEMOAM

Andrea Monteiro Tarragô

Foundation of Hematology and Hemotherapy of Amazonas, HEMOAM

Júlio Nino de Souza Neto

Federal University of Amazonas (UFAM), Manaus

Spartaco Astolfi Filho

Federal University of Amazonas (UFAM), Manaus

Gemilson Soares Pontes

National Institute of Amazonian Research

Antônio Alcirley da Silva Balieiro

Postgraduate Program in Parasitic Biology, Oswaldo Cruz Institute, Rio de Janeiro, RJ

Rachele Isticato Isticato

University of Naples Federico II

Ezio Ricca

University of Naples Federico II 
Luis André M. Mariúba ( $\square$ andre.mariuba@fiocruz.br )

Leônidas e Maria Deane Institute- ILMD-FIOCRUZ-AM

\section{Research Article}

Keywords: Plasmodium falciparum, Circumsporozoite protein, Bacillus subtilis, Spores

Posted Date: August 18th, 2021

DOl: https://doi.org/10.21203/rs.3.rs-777937/v1

License: (c) (1) This work is licensed under a Creative Commons Attribution 4.0 International License. Read Full License

Version of Record: A version of this preprint was published at Scientific Reports on January 27th, 2022. See the published version at https://doi.org/10.1038/s41598-022-05344-2. 


\section{Abstract}

Malaria remains a widespread public health problem in tropical and subtropical regions around the world, and there is still no vaccine available for full protection. In recent years, it has been observed that spores of Bacillus subtillis can act as a vaccine carrier and adjuvant, promoting an elevated humoral response after co-administration with antigens either coupled or integrated to their surface. In our study, $B$. subtillis spores from the KO7 strain were used to couple the recombinant CSP protein of $P$. falciparum ( $\mathrm{rPfCSP}$ ), and the nasal humoral-induced immune response in Balb/C mice was evaluated. Our results demonstrate that the spores coupled to rPfCSP increase the immunogenicity of the antigen, which induces high levels of serum IgG, and with balanced Th1/Th2 immune response, being detected antibodies in serum samples for 250 days. Therefore, the use of $B$. subtilis spores appears to be promising for use as an adjuvant in a vaccine formulation.

\section{Introduction}

Malaria remains a serious public health problem worldwide and causes high morbidity and mortality in tropical and subtropical regions. In 2019, 229 million cases of malaria and 409 thousand deaths were registered worldwide, with Plasmodium falciparum being responsible for the majority of these deaths ${ }^{2}$.

As yet, there is no effective vaccine to combat malaria, though there is a promising candidate, namely the RTS'S vaccine, which targets the pre-erythrocytic stage of the parasite ${ }^{3}$. The RTS'S vaccine comprises part of the central repeat domain and the $C$-terminal region of the $P$. falciparum circumsporozoite surface protein (PfCSP) and presents T-cell epitopes fused to hepatitis B surface antigen ${ }^{4}$. RTS'S is the first malaria vaccine to reach phase III of clinical trials. The tests were carried out among children aged 5-17 months, who received three doses of the vaccine. The children showed a reduction of $39 \%$ in mild and $31.5 \%$ in severe cases of malaria. However, this partial protection tends to decrease with time, and its effectiveness is age-dependent ${ }^{5}$.

Recently, a new vaccine candidate for malaria, known as R21, has shown promising results in clinical trials. R21 has the same CSP sequence as the RTS'S vaccine, though a different adjuvant formulation. Preliminary results from the phase II clinical trial carried out with children aged 5-17 months demonstrated that the R21 vaccine has a long-term efficacy of $77 \%{ }^{6}$. The aforementioned study demonstrated the important role of adjuvants in vaccine efficacy. Therefore, the search for new adjuvants is crucial to the development of effective vaccines since the increase of antigen immunogenicity causes the immune response to provide long-term protection?

Bacillus subtilis spores have proven to be a valuable tool for stimulating stronger immune responses by enhancing antigen presentation and T cell priming 8,9,10. After the integration of antigens in the surface of spores by coupling or recombination, it was observed that they act as adjuvants in different routes of administration, and stimulate the production of pro-inflammatory cytokines and the recruitment/maturation of dendritic cells ${ }^{11,12,13}$. In addition, these spores can induce high levels of IgA 
and IgG neutralizing antibodies and amplify the cellular response of $\mathrm{T} \mathrm{CD} 4^{+} / \mathrm{CD} 8^{+}$antigen-specific cells ${ }^{14,-17}$. Other studies have demonstrated that $B$. subtilis is also recognized by TLR2, TLR4, and TLR9 and can induce Th1/Th2 responses, with the presence of IgG2a and IgG1 in immunized mice sera ${ }^{1819}$.

Therefore, since Bacillus subtilis spores can act as a remarkable carrier for antigen delivery, we present here the first description of the use of $B$. subtilis spores as a novel adjuvant strategy for intranasal vaccination against malaria in a murine model. The recombinant PfCSP ( $P f C S P)$ production and the analysis of the humoral response (total IgG and subclasses) of the immunized animals against this antigen are described.

\section{Materials And Methods}

Recombinant Plasmodium falciparum CSP production. For the design of the recombinant protein of $P$. falciparum CSP ( $r P f C S P)$, we used the sequence proposed by Stoute et al. $(1997)^{20}$ present in commercial malaria vaccine RTS'S. The synthetic gene was produced by the Thermofisher company. It presents an improvement of the codons for expression in E. coli and was inserted in PRSET " $A$ " expression vector. The expression and purification of the recombinant protein were carried out following the methodology described by Souza et al. (2014) ${ }^{21}$. The E. coli BL21 (DE3) pLysS strain was transformed with this construction and induced to produce the recombinant protein using IPTG (isopropyl $\beta$-D-1-thiogalactopyranoside), at a final concentration of $1 \mathrm{mM}$, for $3 \mathrm{~h}$ at $37^{\circ} \mathrm{C}$ in Lurian Bertani medium, containing the antibiotics chloramphenicol $(11.4 \mathrm{ug} / \mathrm{mL})$ and ampicillin $(100 \mathrm{ug} / \mathrm{mL})$. Protein purification was performed using the NTA nickel column (QIAGEN), following the guidelines described by the manufacturer. In order to analyze the expression and purification of the rPfCSP protein, SDS-PAGE was performed following the protocol of Maniatis et al. (1989). Protein mass in SDS-PAGE was determined using the iBright analysis software (Thermo Fisher Connect ${ }^{\text {T'}}$ ). After purification, immunoblots were performed using $r P f C S P$ on a nitrocellulose membrane, and a monoclonal antibody $(\mathrm{mAb})$ for detection of the 6xHis tag (recognized sequence HHHHHHG, Sigma-Aldrich, cat. No. MA1-21315) and an mAb against $P$. falciparum CSP (recognized sequence NANPNVDPNANP, kindly provided by BEI Resources, cat. No. MRA-183A 2A10), as the primary antibody. Developing was performed using an anti-lgG mouse coupled with horseradish peroxidase (KPL, cat. No. 215-1802) and 3,3'-diaminobenzidine (DAB, SigmaAldrich. cat. No. D7304).

Preparation and quantification of B. subtilis spores. The spores of Bacillus subtilis, strain $\mathrm{KO}$, were obtained by the nutrient exhaustion method, using Difco sporulation medium, at $37^{\circ} \mathrm{C}$, under constant agitation for $72 \mathrm{~h}$. Afterwards, the spores were centrifuged at 4,000 rpm for $20 \mathrm{~min}$, washed twice with Milli-Q water, and left for $16 \mathrm{~h}$ at $4^{\circ} \mathrm{C}$. The sample was deactivated by autoclaving at $121^{\circ} \mathrm{C}$, for $45 \mathrm{~min}$. Spore quantification was performed by flow cytometry using FACSCanto (BD) and a Trucount kit (BD), following the manufacturer's guidelines and the method described in Patent US20040023319A1 (supplementary Fig. 1). 
Coupling of r Pf CSP to the spores' surface. Coupling was performed according to the method described by Falahati-pour et al. ${ }^{22}$. The B. subtilis spores at $1 \times 10^{8}$ were resuspended with $250 \mu \mathrm{L}$ of 1 -ethyl-3-(3dimethylaminopropyl) carbodiimide (EDC) $(5 \mu \mathrm{g} / \mathrm{ml})$ and left at room temperature for 15 minutes. Then, $250 \mu \mathrm{L}$ of $\mathrm{N}$-hydroxysuccinimide (NHS) $(5 \mu \mathrm{g} / \mathrm{ml})$ were added, and the sample was incubated at $4{ }^{\circ} \mathrm{C}$ for 30 minutes under agitation. Afterwards, the samples were centrifuged and placed in contact with $10 \mu \mathrm{g}$ of rPfCSP for $16 \mathrm{~h}$ at room temperature, under constant agitation. Subsequently, the spores were then washed 3 times with $0.01 \mathrm{M}$ phosphate saline buffer (PBS), and finally resuspended in $600 \mu \mathrm{L}$ of PBS, and were stored at $4^{\circ} \mathrm{C}$ until the moment of use. The dot blot method was used to quantify the remaining protein in the supernatant after the coupling assay. A curve with varying amounts of supernatant of the $\mathrm{rPfCSP}+\mathrm{SBSKO7}$ coupled sample $(25 \mu \mathrm{l}, 12 \mu \mathrm{l}, 6 \mu \mathrm{l}, 3 \mu \mathrm{l})$, as well as dilutions of purified rPfCSP protein (2 $\mu \mathrm{g} ; 1 \mu \mathrm{g} ; 0.5 \mu \mathrm{g} ; 0.25 \mu \mathrm{l} ; 0.125 \mu \mathrm{l} ; 0.06 \mu \mathrm{l})$ to be used as the standard, were applied under vacuum to the nitrocellulose membrane (Amersham ${ }^{\mathrm{TM}}$ Protran ${ }^{\circledR}$ ) using the Bio-Dot device (BIO-RAD). The nitrocellulose membrane was blocked in 5\% bovine serum albumin BSA solution dissolved in PBS $1 \mathrm{x}$ for $1 \mathrm{~h}$ at room temperature. The membrane was subjected to washings with PBS $1 x$-Tween 80 at $0.05 \%$ and incubations with anti-CSP monoclonal antibody (BEI Resources, cat. No. MRA-183A 2A10) at a 1:1000 ratio and antimouse IgG secondary antibody conjugated to phosphatase alkaline (Phosphatase-KPL) in the proportion 1:10000 for $1 \mathrm{~h}$. Detection was performed with the chromogen of the WesternBreeze ${ }^{\circledR}$ kit (Thermo-Fisher Scientific) following the manufacturer's recommendations. Sample quantification was obtained after scanning and analyzing the membrane image using the program iBright analysis software (Thermo Fisher Connect ${ }^{\text {'m) }}$. Based on a protein concentration curve, it was determined the total amount of remaining $\mathrm{rPfCSP}$ in the specific volume of supernatant. Subtracting the original amount of protein used $(10 \mu \mathrm{g})$ and the remaining amount, it was determined the average percentage of protein which coupled to Bacillus subtilis spore surface.

Nasal Immunization The nasal immunization regime and experimental design was based on Santos et al. $(2020)^{13}$, with some alterations made by our group. A total of 25 female animals (Mus musculus Balb/c) were used and divided into 5 groups containing 5 animals in each: (1) $10 \mu \mathrm{g} \mathrm{rPfCSP}$ coupled to $B$. subtilis spores at $1 \times 10^{8}$ (rPfCSP + SBsK07); (2) only $10 \mu \mathrm{g}$ rPfCSP; (3) Immunization only with spores of $B$. subtilis $1 \times 10^{8}$ (SBsK07); (4) Immunization only with 0.01 M PBS; and (5) Unimmunized mice. Mice were intranasally vaccinated on days 0,14 and 21 of the experiment. The study was authorized by the Ethics Committee on Animal Use of the National Institute for Amazonian Research (CEUA-INPA) under number 031/2018 according to international recommendations for ethics in animal experimentation (ARRIVE guidelines) and by guidelines for animal use and care based on the standards established by National Council for the Control of Animal Experimentation (CONCEA). Enzymatic linked immunosorbent assays (ELISA) were used for the evaluation of the humoral response. For this, blood samples were collected on days zero (D0), D14, D21 and D35 in all groups, and D50, D100, D150, D200 and D250 in groups that presented antibody titers detected by ELISA until D35 (Fig. 2A).

Indirect ELISA. 96-well plates were sensitized with rPfCSP, which was diluted in carbonate buffer ( $\mathrm{pH}$ 9.6) and incubated overnight at $4^{\circ} \mathrm{C}$. Next, plates were washed with $0.01 \mathrm{M} \mathrm{PBS} / 0.05 \%$ of Tween 20 , and the 
wells were blocked using $10 \mathrm{mM}$ PBS $/ 2.5 \% \mathrm{BSA}$ at $37^{\circ} \mathrm{C}$, for 1 hour. The mice sera were diluted at 1:100 in $10 \mathrm{mM} \mathrm{PBS} / 2.5 \% \mathrm{BSA}$, which was added to the wells, and incubated at $37^{\circ} \mathrm{C}$ for $1 \mathrm{~h}$. Then, the plates were washed 4 times with $10 \mathrm{mM}$ PBS/0.05\% Tween 20, and the secondary antibody (anti-lgG mouse HRP conjugate, ZyMax) was added at 1:2000 dilution, and subsequently incubated at $37^{\circ} \mathrm{C}$, for $1 \mathrm{~h}$. The plates were washed again, and the development was carried out with a chromogenic substrate (Scienco One Step - TMB), which was added to each well for 20 minutes. Finally, the reaction was interrupted with $\mathrm{H}_{2} \mathrm{SO}_{4}(2 \mathrm{M})$. The optical density (OD) was determined using an ELISA plate reader (Molecular DevicesFlexStation 3) with a $450 \mathrm{~nm}$ filter. The same procedure was performed for the detection of IgG antibody subclasses, and the secondary antibody was replaced with isotype-specific antibodies against mouse $\lg$ G1, IgG2a, IgG2b and IgG3 (Sigma-Aldrich ${ }^{\circledR}$ ), which was diluted according to the manufacturer's instructions.

Statistical analysis. The results were analyzed using the mixed linear models in order to determine the variations between the groups of animals. All analyses were performed using R software version 4.0.2, and $R$ studio version 1.1.4. The significance level considered was $p<0.05$.

\section{Results}

\section{Recombinant Plasmodium falciparum CSP was successfully expressed and purified from the soluble phase}

The recombinant CSP from Plasmodium falciparum ( $\mathrm{rPfCSP}$ ) used in this study comprises part of the central or repeat region (NANP), and the entire C-terminal region without the GPI anchor (Figure 1A). Electrocompetent Escherichia coli, strain BL21 (DE3) pLysS, were transformed with the expression plasmid pRSET A containing the rPfCSP gene sequence (Figure 1B). The designed protein was successfully expressed and purified along with a polyhistidine tag and was present in the soluble portion of the bacterial lysate. Around 0.5 to $1 \mathrm{mg}$ per liter of bacteria culture was obtained. After induction, the protein had an apparent molecular mass of around $33 \mathrm{kDa}$ (Figure 1C). Other higher-mass proteins around $120 \mathrm{kDa}$ and $63 \mathrm{kDa}$ were also observed (Supplementary figure 2A). Immunoblot using anti-6xHIS tag (Line 1 figure 1D) and anti-PfCSP monoclonal antibodies (Line 2, figure 1D) recognized rPfCSP in the apparent molecular mass and in higher-mass proteins, confirming that all of them correspond to the designed recombinant PfCSP, and supplementary figure 2B.

\section{Adsorption of recombinant PfCSP on B. subtilis spores}

$1 \times 10^{8}$ purified spores of $B$. subtilis were used to adsorb $10 \mu \mathrm{g}$ of $\mathrm{r} P f C S P$. The efficiency of adsorption was evaluated by dot blotting as previously reported (8). The analysis revealed that about $50-65 \%$ of the $\mathrm{rPfCSP}$ used in the reaction were stably adsorbed to spores (Supplementary Figure 3). Based on the results of the dot blot analysis, $1 \times 10^{8}$ adsorbed spores were used to nasally inoculare mice, therefore delivering $5-6.5 \mu \mathrm{g}$ of $\mathrm{r} P f C S P$ per dose to each of the immunized animal 


\section{Bacillus subtilis spores coupled to rPfCSP were capable of inducing IgG production via intranasal immunization}

The rPfCSP+SBsK07 group induced high levels of serum IgG anti-rPfCSP on D14 and reached the highest levels of IgG on D100 and D150.The group immunized with only rPfCSP also induced the production of IgG. However, a detectable level of IgG anti-rPfCSP was only observed on D35 and reached the highest levels also on D100 and D150, though these were significantly lower when compared to the $\mathrm{rPfCSP}+\mathrm{SBsKO7}$ group (Figure 2B). No significant concentration of IgG anti-rPfCSP was detected in the negative control (SBSKO7, PBS, and unimmunized group).

Anti-rPfCSP titers were significantly higher in the rPfCSP+SBsK07 group on D14, D21, D35, D50, D200 and D250, when compared to the rPfCSP group (Figure 2B). Predictions made via statistical analysis demonstrated that the rPfCSP+SBsKO7 and rPfCSP groups presented anti-rPFCSP at the same level of negative control on D262 and D243, respectively. These results indicate that the rPfCSP delivered through $B$. subtilis spores induces the production of longer-lasting antibodies.

\section{IgG subclass profiles}

The $\mathrm{P} P f C S P+S B S K 07$ group showed the highest serum levels for $\lg \mathrm{G} 1$, IgG2a, IgG2b and, IgG3 subclasses on D14, D21, D150, D200, and D250 when compared to the rPfCSP group (Figure 3). The subclass IgG2b showed the highest levels in both groups, followed by $\lg \mathrm{G} 2 \mathrm{a}, \lg \mathrm{G} 1$, and $\lg \mathrm{G} 3$. The difference between the $\mathrm{rPfCSP}+\mathrm{SBSKO7}$ and $\mathrm{rPfCSP}$ groups observed in the IgG subclasses were statistically significant over the 250 days, except in the case of $\lg G 1$ and $\lg 22 a(\lg G 2 b>\lg G 2 a=\lg G 1>\lg G 3)$ (Supplementary figure 4 ).

\section{Discussion}

The PfCSP was the first malaria protein cloned and recommended for use as an immunogen in malaria vaccine candidates ${ }^{23}$. Since then, significant efforts have been made to investigate the functional characteristics of this protein ${ }^{24}$. In this study, we produced a recombinant form of the PfCSP, which presented bands near and above the predicted molecular weight in SDS-PAGE analysis. All bands were recognized by anti-PfCSP monoclonal antibodies, including the bands higher than expected, which, probably correspond to some rPfCSP that may not denature completely. Noe et al. $(2014)^{25}$ also reported the presence of a band at approximately $120 \mathrm{kDa}$ after purification of a recombinant CSP, which was reduced when the SDS-PAGE denaturation buffer was changed. Thus, the authors concluded that the band corresponded to a dimeric form of recombinant CSP. Other studies have also reported the presence of bands above the initially predicted mass during the expression of $r P f C S P$, indicating that there is significant interaction between $r P f C S P$ units even in a reduced condition ${ }^{26,27}$.

Our findings showed that Bacillus subtilis spores expressing surface-exposed $\mathrm{r} P f C S P$ induced a significant improvement in anti-rPfCSP IgG levels in mice sera after nasal administration. Additionally, no cross-reactivity between the $r P f C S P$ and the serum from the mice immunized with only $B$. subtilis was observed, which confirms that the observed increase in the lgG level of the anti-rPfCSP in rPfCSP + 
SBsK07 group was due to the adjuvant properties of the $B$. subtilis spores. Similar findings have been reported by previous studies $8,9,11,28,29$.

As such, the present study corroborates with others, and demonstrates the ability of the $B$. subtilis spores to induce high levels of serum IgG against vaccine antigens through nasal immunization ${ }^{9,14,30,31}$. Song et al. (2012) $)^{14}$ observed higher levels of systemic IgG in mice nasally immunized with $B$. subtilis spores adsorbed with H5N1 virus when compared to animals that received the inactivated virus alone.

Futhermore, Lee et al. (2010) ${ }^{28}$ also found that mice immunized with $B$. subtilis spores expressing the bovine rotavirus VP6 protein were able to produce increased serum levels of anti-VP6 IgG and anti-VP6 fecal IgA antibodies, while the animals immunized with the VP6 protein alone induced only serum IgG antibodies. In addition, the antibodies produced were able to protect the mice when challenged with rotavirus. High levels of specific antibodies were also found in animals nasally immunized with $B$. subtilis expressing Ig85 and Ag85B antigens ${ }^{29}$. These studies demonstrated the great potential of the $B$. subtilis spores as a nasally delivered vaccine adjuvant.

Circulating antibodies are considered critical mediators of effective immunity against malaria parasites during sporozoites stage ${ }^{3}$. The follow-up of anti-PfCSP antibodies levels in blood serum is crucial to determine whether the potential adjuvant can promote long-term humoral response. The present study was the first one to follow the antibody response after immunization with a $B$. subtilis spores-based antigen for 250 days, which made it possible to observe and compare the intensity of the murine humoral response. The antibody responses elicited by $B$. subtilis spores were faster, greater and longer (high antibody titers over 250 days) than those observed in the control groups. Increased anti-rPfCSP IgG titers was observed between 14-21 weeks post-immunization.

The pattern of humoral responses induced by platform-based vaccines depends on many factors such as the nature and immunogenicity potency of an antigen, immunization delivery strategy and animal model. Mou et al. (2016) orally immunized chickens using B. subtilis recombined with the H5N1 protein of the avian influenza virus. The highest serum antibody levels were observed after $3-5$ weeks postimmunization ${ }^{15}$. Jelínková et al. (2021) reported the presence of serum anti-PfCSP IgG antibodies even after almost two years post-immunization with non-infectious virus particles expressing PfCSP. In this case, the immunization was more effective when they added an adjuvant. This highlights once more the importance of the search for new adjuvant for enhancing the quality of the immune response induced by different vaccine approaches, as described previously 32,33 .

The immunization strategies used in this study induced mainly high serum levels of IgG2b and IgG2a subclasses, followed by $\lg \mathrm{G} 1$, and low levels of $\lg \mathrm{G} 3$. The use of $B$. subtilis spores did not interfere in the IgG subclass pattern produced, but it did enhance the levels of antibody titers. The pattern of antibody immune responses continued unaltered until day D250, which suggests that our spore-based approach induced a mixed Th1/Th2 immune response profile, since lgG2a/b are Th2-related isotypes, while lgG1 is associated with the Th1-type response ${ }^{37,38,39}$. Santos et al. $(2020)^{13}$ reported a mixed Th1/Th2 response 
generated after using TTFC antigen adsorbed on nasally administered $B$. subtilis spores. De Souza et al. $(2014)^{11}$ observed the induction of Th1-dependent IgG2a or Th2-dependent IgG1 antibodies when p24 HIV protein were co-administered with $B$. subtilis spores.

A possible explanation for the modulation of the immune response induced by $B$. subtilis spores is that it promotes an efficient and direct antigen presentation via $\mathrm{MHC}$ class $\mathrm{I} / \mathrm{II}$ and, leading to a balanced humoral and cellular response ${ }^{18,39,41}$. However, in this study, we did not assess cellular immunity induced by the $B$. subtilis spore-based vaccine strategy used.

In humans, production of cytophilic antibodies, $\lg G 3$ and $\lg \mathrm{G} 1$, as observed in the Th1 response is reported to be associated with protection in malaria ${ }^{34,35,40}$. In mice, high levels of $\lg \mathrm{G} 2 \mathrm{a} / \mathrm{b}$ characterize a Th1 response, since it presents a cytophilic function, acting in complement fixation and pathogen opsonization and, promoting a more efficient fagocytosis than $\lg \mathrm{I}^{37,38}$. The results observed in this study demonstrated the improvement in the production of cytophilic antibodies after the use of $B$. subtilis spores as an adjuvant and antigen carrier.

\section{Conclusion}

We present here the first evaluation of the use of a Bacillus subtilis spore-based adjuvant/antigen carrier for a malaria vaccine strategy and the humoral response induced by this approach over a period of 250 days of follow-up. The data indicate that the use of this spore could stimulate a greater, faster, and longer antibody response against the PfCSP antigen. In addition, this vaccine approach is very promising because it may induce a balanced Th1/Th2 immune response. Additional studies are necessary in order to reveal the cellular immunity involved in the immune response elicited by the recombinant $B$. subtilis spores expressing PfCSP.

\section{Declarations}

\section{Acknowledgments}

The authors would like to thank the Programa de Pós-Graduação Stricto Sensu em Biologia Celular e Molecular do Instituto Oswaldo Cruz (IOC/Fiocruz), Rio de Janeiro, RJ, Brazil, for the financial support; to the Program for Thechnological Development in Tools for Health PDTIS-FIOCRUZ (RPT-08J) for uso of its facilities; to the Centro de Apoio Multidisciplinar (CAM) of the Federal University of Amazonas for helping to obtain the recombinant protein; the BEI Resources for kindly donating the Anti-CSP monoclonal antibody and the National Institute of Amazonian Research's central vivarium for their support in the animal manipulation experiments.

\section{Author contributions}

LAMM, MEMA and GSP conceived the study and designed the study protocol; MEMA, MGSV, TSP, JCG, JNSN and SAF performed the production of the recombinant protein; EZ, GSP, RI, JNSN and SAF revised 
the study protocols and provided reagents; MESMA, LAMM, AASB, WLLN, YOC and GSP performed the analysis and interpretation of the data; MEMA, KCSA, MGSV and TSP performed the animal manipulation experiments; MEMA, KCSA, JCG, WLLN, AMT, GSP, ER, AASB LAMM wrote the manuscript; and critically revised the manuscript for intellectual content; LAMM obtained the funding for the study. All authors read and approved the final manuscript.

\section{References}

1. World Health Organization (WHO). World Malaria Report 2020.

2. Greenwood, B \& Targett, G. Do we still need a malaria vaccine? Parasite Immunol. 31, 582-6 (2009).

3. Kurtovic, L, et al. Complement in malaria immunity and vaccines. Immunol Rev. 293, 38-56 (2020).

4. Bejon, P. et al. Efficacy of RTS'S/AS01E vaccine against malaria in children 5 to 17 months of age." The New England journal of medicine. 24, 2521-32 (2008).

5. RTS'S Clinical Trials Partnership. Efficacy and safety of the RTS'S/AS01 malaria vaccine during 18 months after vaccination: a phase 3 randomized, controlled trial in children and young infants at 11 African sites. PLoS Medicine. 11, e1001685 (2014).

6. Datoo, M. S. et al. Efficacy of a low-dose candidate malaria vaccine, R21 in adjuvant Matrix-M, with seasonal administration to children in Burkina Faso: a randomised controlled trial. Lancet. 397, 1809-1818 (2021).

7. Wang, L.T. et al. A Potent Anti-Malarial Human Monoclonal Antibody Targets Circumsporozoite Protein Minor Repeats and Neutralizes Sporozoites in the Liver. Immunity. 53, 733-744 (2020).

8. Isticato R. et al. Non-recombinant display of the B subunit of the heat labile toxin of Escherichia coli on wild type and mutant spores of Bacillus subtilis. Microb Cell Fact. 29, 98 (2013).

9. Mauriello, E.M. et al. Display of heterologous antigens on the Bacillus subtilis spore coat using CotC as a fusion partner. Vaccine. 12, 9-10 (2004).

10. Zhou, Z. et al. Expression of Helicobacter pylori urease B on the surface of Bacillus subtilis spores. J. Med Microbiol. 64,104-10 (2015).

11. De Souza, RD, et al. Bacillus subtilis spores as vaccine adjuvants: further insights into the mechanisms of action. PLoS One. 9, e87454 (2014).

12. Copland, A, et al. Mucosal Delivery of Fusion Proteins with Bacillus subtilis Spores Enhances Protection against Tuberculosis by Bacillus Calmette-Guérin. Front Immunol. 9, 346 (2018).

13. Santos, $F$, et al. A probiotic treatment increases the immune response induced by the nasal delivery of spore-adsorbed TTFC. Microbial cell factories. 19, 42 (2020).

14. Song $\mathrm{M}$, et al. Killed Bacillus subtilis spores as a mucosal adjuvant for an H5N1 vaccine. Vaccine. 9, 3266-77 (2012).

15. Mou C et al. Immune Responses Induced by Recombinant Bacillus subtilis Expressing the Hemagglutinin Protein of H5N1 in chickens. Scientific reports. 6, 38403 (2016). 
16. Barnes A.G, Cerovic V, Hobson PS, Klavinskis LS. Bacillus subtilis spores: a novel microparticle adjuvant which can instruct a balanced Th1 and Th2 immune response to specific antigen. Eur $J$ Immunol. 37, 1538-47 (2007).

17. Zhang, S, Mou C, Cao Y, Zhang E \& Yang, Q. Immune response in piglets orally immunized with recombinant Bacillus subtilis expressing the capsid protein of porcine circovirus type 2. Cell Commun Signal. 18, 23 (2020).

18. Huang, J.M, et al. Mucosal delivery of antigens using adsorption to bacterial spores. Vaccine.28, 1021-30 (2010).

19. Wang, Y, et al. Mucosal and systemic immune responses induced by intranasal immunization of recombinant Bacillus subtilis expressing the P97R1, P46 antigens of Mycoplasma hyopneumoniae. Biosci. Rep. 39, 10 (2019).

20. Stoute, JA, et al. A preliminary evaluation of a recombinant circumsporozoite protein vaccine against Plasmodium falciparum malaria. RTS'S Malaria Vaccine Evaluation Group. N Engl J Med. 336, 86-91 (1997).

21. Sousa, $L$, et al. A novel polyclonal antibody-based sandwich ELISA for detection of Plasmodium vivax developed from two lactate dehydrogenase protein segments. BMC infectious diseases, 14, 49 (2014).

22. Falahati-Pour, S.K, Lotfi, A.S, Ahmadian, $G$ \& Baghizadeh, A. Covalent immobilization of recombinant organophosphorus hydrolase on spores of Bacillus subtilis. J App/ Microbiol. 118, 976-88 (2015).

23. Arnot, D,E, et al. Circumsporozoite protein of Plasmodium vivax. gene cloning and characterization of the immunodominant epitope. Science. 230:815-8 (1985).

24. Heide, J, Vaughan KC, Sette A, Jacobs T, Schulze \& Zur Wiesch J. Comprehensive review of human Plasmodium falciparum-Specific CD8+ T cell epitopes. Front Immunol. 21, 10:397 (2019).

25. Noe, AR, et al. A full-length Plasmodium falciparum recombinant circumsporozoite protein expressed by Pseudomonas fluorescens platform as a malaria vaccine candidate. PLoS One. 23, e107764 (2014).

26. Plassmeyer, ML, et al. Structure of the Plasmodium falciparum circumsporozoite protein, a leading malaria vaccine candidate. J Biol Chem. 284, 26951-63 (2009).

27. Oyen, D, et al. Structural basis for antibody recognition of the NANP repeats in Plasmodium falciparum circumsporozoite protein. Proceedings of the National Academy of Sciences of the United States of America. 114, E10438-E10445 (2017).

28. Lee, S, et al. Development of a Bacillus subtilis-based rotavirus vaccine. Clin Vaccine Immunol. 17,1647-55 (2010).

29. Das, K, Thomas, T, Garnica, O \& Dhandayuthapani, S. Recombinant Bacillus subtilis spores for the delivery of Mycobacterium tuberculosis Ag85B-CFP10 secretory antigens. Tuberculosis (Edinb). 101S:S18-S27 (2016).

30. Dai, X, Liu, M, Pan, K, \& Yang, J. Surface display of OmpC of Salmonella serovar Pullorum on Bacillus subtilis spores. PloS one, 13, e0191627 (2018). 
31. Zhang, S, Mou, C, Cao, Y, Zhang, E \& Yang, Q. Immune response in piglets orally immunized with recombinant Bacillus subtilis expressing the capsid protein of porcine circovirus type 2. Cell Commun Signal. 18, 23 (2020).

32. Jelínková, L, Jhun, H, Eaton, A, Petrovsky, N, Zavala, F \& Chackerian, B. An epitope-based malaria vaccine targeting the junctional region of circumsporozoite protein. NPJ Vaccines. 6, 13 (2021).

33. Huang, WC, et al. A malaria vaccine adjuvant based on recombinant antigen binding to liposomes. Nat Nanotechnol. 12, 1174-1181 (2018).

34. John CC, et al. Antibodies to pre-erythrocytic Plasmodium falciparum antigens and risk of clinical malaria in Kenyan children. $J$ Infect Dis. 197, 519-26. (2008).

35. Perez-Mazliah D, Langhorne J. CD4 T-cell subsets in malaria: TH1/TH2 revisited. Front in Immunol. 5, 671. (2015).

36. Dobaño C. et al. Differential Patterns of IgG Subclass Responses to Plasmodium falciparum Antigens in Relation to Malaria Protection and RTS,S Vaccination. Front in Immunol. 10, 439. (2019).

37. Waldmann H. Manipulation of T-cell responses with monoclonal antibodies. Annu Rev Immunol. 7, 407-44. doi: 10.1146/annurev.iy.07.040189.002203. (1989).

38. White WI, Evans CB, Taylor DW. Antimalarial antibodies of the immunoglobulin G2a isotype modulate parasitemias in mice infected with Plasmodium yoelii. Infect Immun. 59, 3547-3554. doi:10.1128/iai.59.10.3547-3554. (1991).

39. Amuguni, H \& Tzipori, S. Bacillus subtilis: a temperature resistant and needle free delivery system of immunogens. Hum Vaccin Immunother. 8, 979-86 (2012).

40. Shabani SH, Zakeri S, Mortazavi Y, Mehrizi AA. Immunological evaluation of two novel engineered Plasmodium vivax circumsporozoite proteins formulated with different human-compatible vaccine adjuvants in C57BL/6 mice. Med Microbiol Immunol. 208, 731-745. doi: 10.1007/s00430-01900606-9. (2019).

41. Amuguni, JH, et al. Sublingually administered Bacillus subtilis cells expressing tetanus toxin $\mathrm{C}$ fragment induce protective systemic and mucosal antibodies against tetanus toxin in mice. Vaccine. 29, 4778-84 (2011).

\section{Figures}




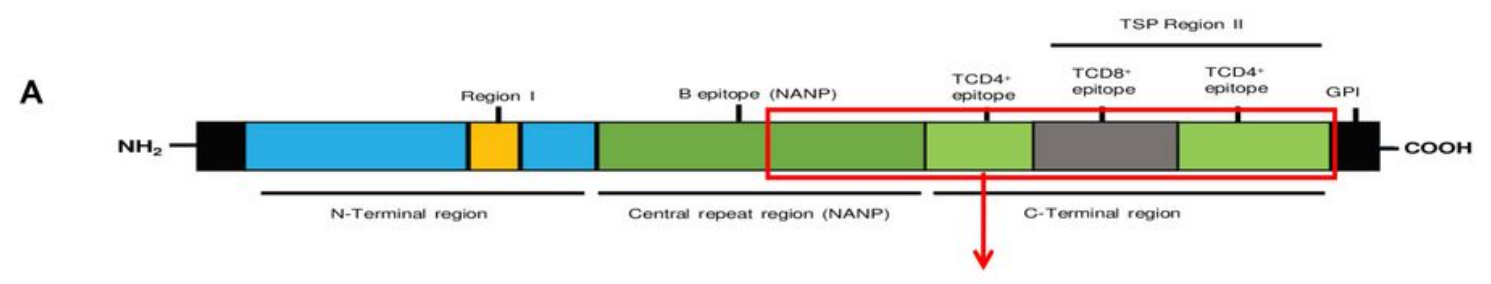

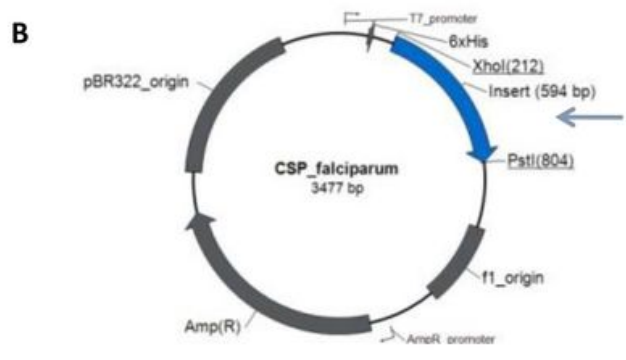

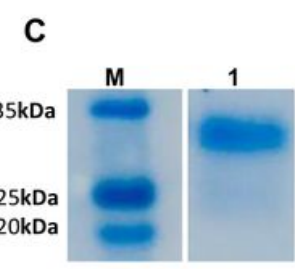

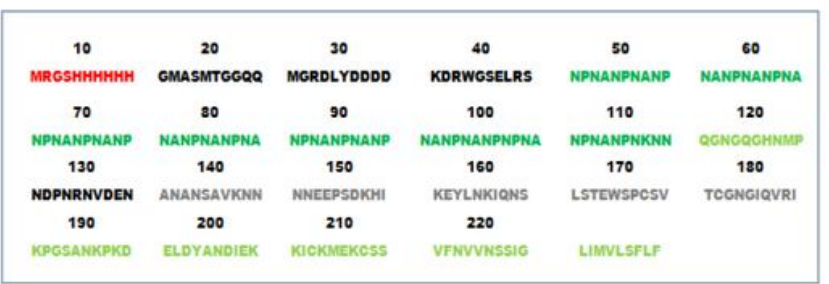

D

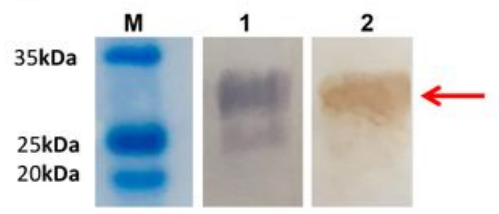

\section{Figure 1}

Construction and confirmation of the expression of the rPfCSP. A: Complete sequence of CSP. The region corresponding to the construction of the rPfCSP developed in this study is highlighted; B: Amino acid sequence corresponding to rPfCSP and the expression plasmid in which it was inserted (pRSET A, Invitrogen); C: SDS-PAGE analysis of recombinant protein, BLUeye Pre-stained ladder (Sigma-Aldrich) (lane M), and electrophoretic profile of two rPfCSP elution (lane 1); western blot confirming the recognition of rPfCSP by anti-HisG monoclonal antibody (lane 2) and anti-PfCSP monoclonal antibody (lane 3). 

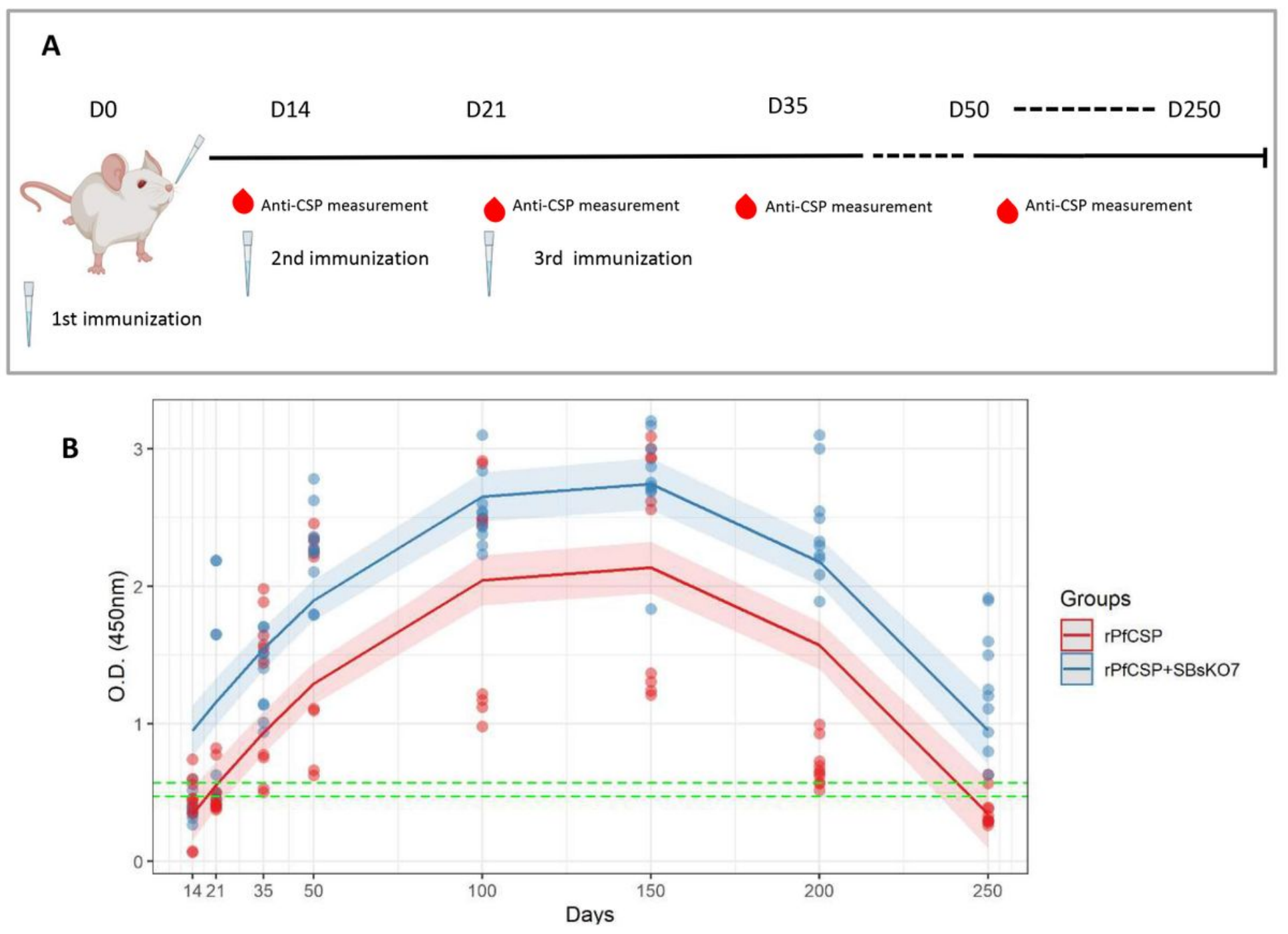

Figure 2

Indirect ELISA quantification of total IgG in mice. A: Schematic showing the nasal immunization regimen and the follow-up period of the humoral immune response in mice. B: Graph showing indirect ELISA quantification of total IgG from mice immunized intranasally with rPfCSP and rPfCSP coupled to SBsKO7 (O.D $450 \mathrm{~nm}$ ) at each blood sample collection day. The horizontal green lines correspond to the negative control variation (only $1 \times 108$ SBsKO7 and PBS mice groups). The blue line corresponds to the mean O.D. $(450 \mathrm{~nm})$ of the group of mice immunized with rPfCSP+SBsK07 for each collection day (D14, D21, D35, D50, D100, D150, D200, and D250) and each blue dot represents the mean of O.D. of a mouse from the group in duplicate. While the red line corresponds to the mean O.D of the group of mice immunized only with rPfCSP and each red dot corresponds to the mean O.D. of ELISA reactivity of a mouse blood sample. It is observed that the confidence bands do not touch each other at any time in the curves for each group, thus demonstrating that the rPfCSP+SBsKO7 group has the highest mean O.D. on all days of the experiment with a significant value of $p<0.001$. The significance level considered was $p<0.05$. 


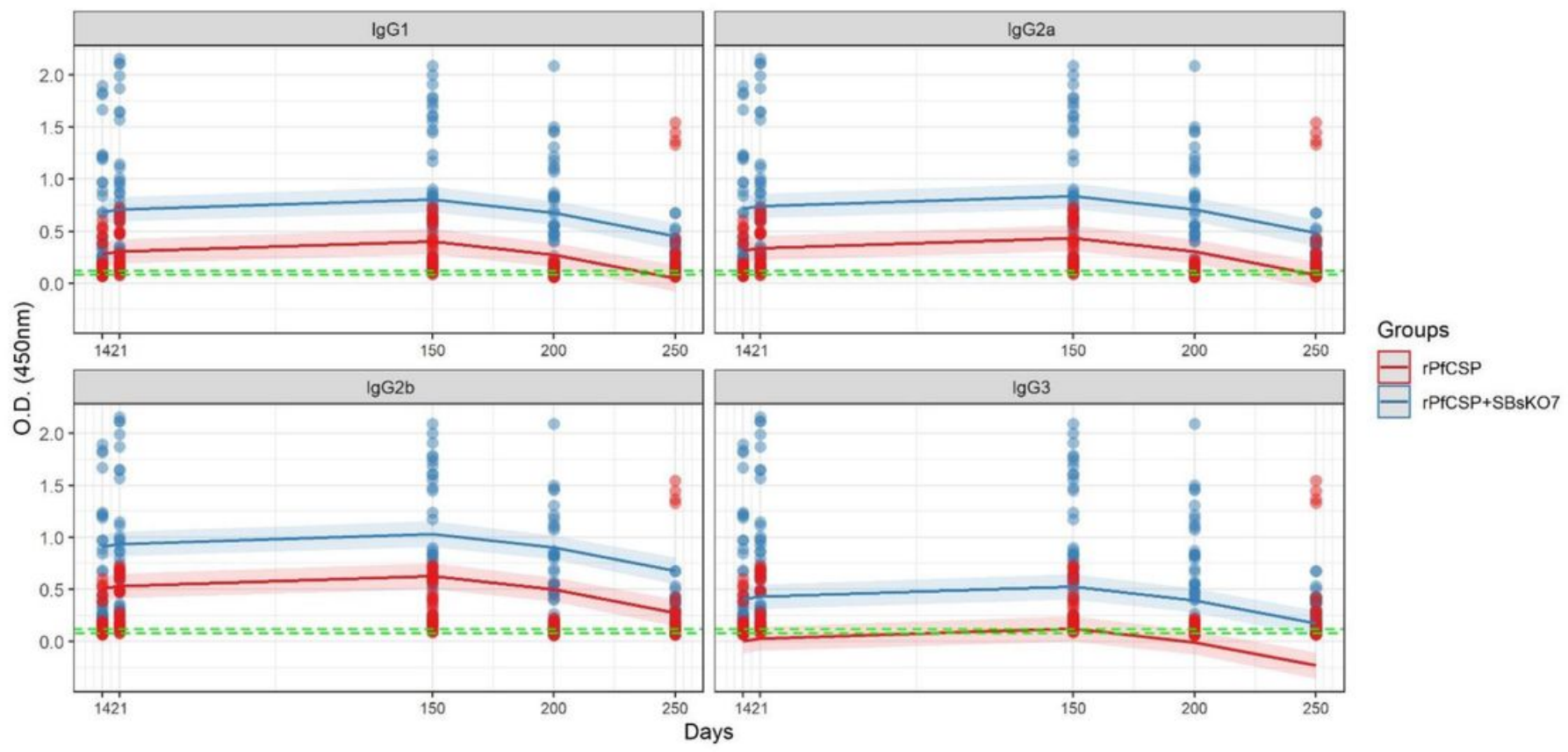

\section{Figure 3}

Indirect ELISA quantification of IgG subclasses in groups immunized only with rPfCSP and with rPfCSP+SBsK07. The green horizontal lines correspond to the negative control variation (SBsK07 1 108 and PBS). Each graph represents the quantification of the $\lg$ G1, $\lg G 2 a, \lg G 2 b$, and $\lg G 3$ subclasses of the rPfCSP (red line) rPfCSP+SBsKO7 (blue line) mice groups. Each point corresponds to the mean O.D. (450 $\mathrm{nm}$ ) of each mouse in the groups for the subclasses, in the previously mentioned colors. The significance level considered was $p<0.05$. Only IgG2a was not significant when compared to IgG 1 and, among the other subclasses, the $p$-value was significant over time.

\section{Supplementary Files}

This is a list of supplementary files associated with this preprint. Click to download.

- FiguresupplementaryAlmeida2021scientificreports.pdfV1.pdf 